\title{
A intermediação sensível e a ética discursiva no processo de letramento acadêmico em contexto de educação à distância
}

\author{
Antoni Carlos Santos de Lima* \\ Rita de Cássia Souto Maior
}

\section{Resumo}

$\mathrm{O}$ presente artigo tem como objetivo analisar o processo de aprendizagem de professores/as em formação inicial dentro das discussões sobre o letramento acadêmico. Utilizando pressupostos teórico-metodológicos da Linguística Aplicada, adotamos a perspectiva interpretativista de pesquisa para analisar momentos presenciais e a distância das interações entre professor e discentes no fórum de discussões e em aulas presenciais de um componente curricular ofertado no primeiro semestre do curso de Letras/Português de um Instituto Federal. Após as análises, concluímos que os acontecimentos observados estão relacionados à condução da aula (em momentos presenciais e não presenciais) não condizente a um processo de letramento acadêmico efetivo e significativo. Para o desenvolvimento de uma prática mais efetiva, concluímos que deveria ocorrer uma prática pedagógica de intermediação sensível, associada à produção numa perspectiva de ética discursiva, para que os/as futuros/as professores/as pudessem atuar atendendo à demanda de uma formação mais autônoma e crítica.

Palavras-chave: Letramento acadêmico. Intermediação sensível. Ética discursiva. Formação docente.
É professor do Instituto Federal de Alagoas (IFAL), educação básica e superior, nas modalidades presencial e a distância, onde desenvolve estudos sobre letramentos, letramento acadêmico, avaliação como intermediação sensível e formação de professores nessas modalidades. Possui graduação em Letras (Português e Inglês) pela Universidade Federal de Alagoas (UFAL) e Especialização em Língua Portuguesa e Literatura Brasileira pela Universidade Cidade de São Paulo (UNICID). É mestre em Linguística pelo Programa de Pós-graduação em Letras e Linguística da Faculdade de Letras (FALE) da UFAL. É doutor pelo mesmo Programa (PPGLL/FALE/UFAL), no qual desenvolveu pesquisa sobre letramento acadêmico em um curso de Letras-Português a Distância do IFAL. Coordena o sistema Universidade Aberta do Brasil (UAB) no âmbito do IFAL desde 2017. Lidera o Grupo de Pesquisa: Educação, Empreendedorismo, Letramento e Tecnologia / EELT-CNPq/IFAL. Integra o Grupo de Estudos Discurso, Ensino e Aprendizagens de Línguas e Literaturas GEDEALL/CNPq/UFAL e o GT da Anpoll: Ensino e Aprendizagem na Perspectiva da Linguística Aplicada/ EAPLA. E-mail: professorantoniolima@gmail.com

* Professora associada da Faculdade de Letras da Universidade Federal de Alagoas (FALE/UFAL) na Graduação e na Pós-graduação. Doutora e mestre em Linguística pelo Programa de Pós-Graduação em Linguística e Literatura (PPGLL/UFAL), foi licenciada em Letras/Português na mesma Universidade. Realizou estudos de pós-doutoramento no Programa de Pós-graduação em Linguística (PPGL/ UFC) pela Universidade Federal do Ceará. Atualmente é diretora da Faculdade de Letras/UFAL, coordenadora do GT Ensino e Aprendizagem na Perspectiva da Linguística Aplicada (EAPLA/ANPOLL) e é secretária da Associação Brasileira de Linguística (Abralin). Participa e é uma das líderes do Grupo de Estudos Discurso, Ensino e Aprendizagem de Línguas e Literatura (GEDEALL/UFAL) e integra, como participante, o Grupo de Estudos e Pesquisas em Linguística Aplicada (GEPLA/UFC). Foi coordenadora do Programa de Iniciação à Docência Língua Portuguesa/Pibid na FALE de 2015 a 2018 e coordenadora do Idioma sem Fronteiras de 2016 a 2018. Articula reflexões sobre o ensino e aprendizagem de Línguas (materna, estrangeira e Libras) e sobre a abordagem discursiva, a partir da perspectiva teórico-metodológica da Linguística Aplicada. Atualmente desenvolve pesquisas com os seguintes temas: Subjetividades; Práticas identitárias; Ethos; Argumentação; Estudos dialógicos bakhtinianos; Produção de textos em LM, LE e Libras; Estudos da ética-discursiva; Saberes e Formação Docentes. Orcid: https://orcid.org/0000-0002-2613-8863. E-mail: ritasoutomaior@gmail.com

Data de submissão: set. 2020 - Data de aceite: nov. 2020 http://dx.doi.org/10.5335/rdes.v16i3.11493 


\section{Introdução}

Quando Bakhtin (2003) afirma que todas as atividades humanas estão relacionadas aos usos da linguagem, entendamos, também com o mesmo teórico, que esses usos se realizam a partir de gêneros discursivos, ou seja, por meio de enunciados que estão a serviço das necessidades interacionais dos sujeitos, em suas atuações sociais de diferentes contextos. Nesse sentido, nos espaços nos quais os sujeitos circulam são requeridos determinados usos da linguagem configurados em gêneros específicos.

O contexto educacional é um desses espaços que, por sua vez, requer determinados usos que atendam às suas demandas, as quais, por sua vez, estão associadas às transformações ocorridas ao longo do tempo. Um fenômeno ilustrativo dessas transformações no campo educacional é a Educação a Distância (doravante $\mathrm{EaD}$ ), que tem crescido não só no Brasil, mas em todo mundo, graças ao advento e à evolução das Tecnologias Digitais de Informação e Comunicação (TDIC), fortemente marcada no final do século XX (CASTELLS, 2009). Nesse contexto de ensino a distância, a interação entre os sujeitos envolvidos no processo ensino/aprendizagem (professores/ as, tutores/as e alunos/as) ocorre, virtualmente, através do uso desses recursos nos quais os textos, enquanto gêneros discursivos, contribuem para a troca e, consequentemente, para a construção de novos saberes. Nesse intercâmbio de conhecimentos, o processo de produção escrita, principalmente por parte dos/as alunos/as, nos dispositivos do ambiente Moodle, requer uma demonstração de aprendizagem que se centra tanto em aspectos linguístico-discursivos, imanentes à prática com o texto por meio de gêneros, quanto em aspectos relacionados à apropriação dos saberes/conhecimentos (LIMA, 2019). Ainda segundo Lima (2019), esses aspectos são constitutivos do letramento acadêmico e, na $\mathrm{EaD}$, são vivenciados em maior escala nos espaços dos fóruns, esses orientados por docentes e tutores/as. Nesse sentido, há alguns encaminhamentos que podem ser ações planejadas e articuladas através da atividade docente, como: sondagem de aspectos relevantes para o aprendizado dentro da temática, reflexão sobre aspectos da linguagem adequados ao gênero e contexto de uso e organização metodológica de avaliação, conduzida a partir de contextualização e de etapas (SOUTO MAIOR, 2018).

Esse processo de aprendizagem, intermediada tanto pelo uso da linguagem quanto pelo ensino da utilização significativa dessa, a nosso ver, também demanda de uma ação docente pautada numa perspectiva de produção ética discursiva (SOUTO MAIOR, 2018), que se trata, basicamente, de debate sobre o que está sendo dito, com responsabi- 
lização sobre o dizer, e sobre a reflexão sobre as implicações desse dizer para a necessária convivência humana, reconhecidamente política e promotora de mudanças sociais, que visem à equidade das condições sociais humanas.

Partindo desses entendimentos, defendemos uma ação docente pautada na perspectiva de uma Intermediação Sensível (LIMA, 2019), que parta da contextualização dos saberes, desnaturalização de práticas e crenças e escuta do outro. Esse movimento busca tanto a desaprendizagem (FABRÍCIO, 2006) de sentidos - que, às vezes, ratificam a estrutura do tradicional sistema de mera reprodução dos saberes, mantenedora da desigualdade socioeconômica de direitos -, quanto o acolhimento das diversidades (de identidade, de saberes, de sentidos, de ideologias) - que provê o aluno de condições para refletir sobre os mais diversos aspectos relacionados ao seu processo de leitura e de escrita no mundo. Zeichner (2011, p. 63), nessa discussão sobre formação docente, entende que "temos escolhas a fazer que nos colocam ou na posição de lutar por mudanças nessa situação ou na posição de contribuir para a manutenção do que aí está", ou seja, "não podemos ficar neutros".

Vários campos de atuação escrita poderiam ser investigados na observância da prática de formação docente, mas nos debruçamos sobre dois mais específicos: o da aula presencial, com padrões de interação que vêm de uma tradição já mais estruturada, e um do gênero que, no contexto da $\mathrm{EaD}$, parece ser um dos mais utilizados, ou pelo menos, é o que registra mais marcadamente o espaço de interação professor/a - aluno/a no campo da educação a distância, a saber, o espaço do fórum. Ambos, o momento da aula presencial e a atuação no gênero fórum parecem propiciar, em tese, o movimento de diálogo e de interação entre os participantes no processo de letramento (LIMA, 2019) que compõe a formação dos/as estudantes.

O letramento acadêmico, que é definido a partir do conjunto de gêneros próprios do campo da escolarização formal, será também nosso enfoque nas práticas de escrita dos/as alunos/as nos espaços de encontro com o outro no contexto que estamos pesquisando, aula presencial e atividade de interação no fórum. Nesses espaços, podemos desenvolver o processo de ensino/aprendizagem da escrita e do dizer sobre temas, ou sobre o outro, nas perspectivas da construção da subjetividade, da incorporação de técnicas, do desenvolvimento do conhecimento crítico dos saberes e da ação social ética.

Nosso objetivo, portanto, é analisar o processo de ensino e aprendizagem de professores/as em formação inicial, no momento de encontro presencial e no fórum de discussões de uma disciplina de um curso de formação docente em Letras $\mathrm{EaD}$, e sua relação com o desenvolvimen- 
to do letramento acadêmico, considerando a perspectiva ética discursiva do processo de escrita pelo que chamamos de intermediação sensível. A partir desse objetivo, algumas questões nortearam nossas discussões, a saber: como se caracteriza a prática do professor no processo de letramento acadêmico dos/as alunos/as em uma turma de Letras EaD? Quais as implicações dessa intermediação no processo de uma escrita pautada numa perspectiva da ética discursiva? Que práticas promoveriam o letramento acadêmico mais condizente com as demandas de uma formação docente mais efetiva e crítica?

Metodologicamente, assumimos a perspectiva interpretativista das pesquisas em Linguística Aplicada (MOITA LOPES, 1996, 2016; FABRÍCIO, 2006), dentro de uma abordagem qualitativa (OLIVEIRA, 2008), que torna "problemática a adoção de pontos de vista e explicações causais simplistas a respeito dos fenômenos sociais" (FABRÍCIO, 2006, p. 47), e a análise histórico discursiva (FREITAS, 2003) dos dados, dentro de um paradigma qualitativo de pesquisa. Foi feita uma observação participante (LÜDKE; ANDRÉ, 1986) por dois meses, período no qual o Lima participou tanto das atividades remotas quanto da atividade presencial da disciplina.

A fim de problematizarmos as informações coletadas, analisamos um momento presencial e uma atividade remota do fórum de discussões da turma Fundamentos da Linguística I, ofertada no primeiro semestre de um curso de Letras-Português à distância de um Instituto Federal, que teve como conteúdo principal as concepções de língua e linguagem. A turma, de um polo situado numa cidade do agreste alagoano, era composta por trinta e cinco alunos/ as, um professor doutor e uma tutora especialista.

A partir das questões supracitadas e para a organização deste texto, apresentaremos, num primeiro tópico teórico, as noções de discurso, ética do discurso, formação docente e intermediação sensível. Para podermos esclarecer um pouco mais sobre o momento não presencial, trataremos da noção de gênero e, mais especificamente, de fórum no ambiente virtual do Moodle, num segundo tópico de discussões. Por fim, apresentamos a metodologia e os procedimentos de análise de dados, para seguirmos com a interpretação do corpus selecionado e produção das reflexões finais.

\section{Discurso e interação: aspectos para a docência}

A partir dos estudos dialógicos (BAKHTIN, 2003, 2005), entendemos que é por meio da língua viva que os sujeitos interagem nas mais variadas esferas sociais e que podem compartilhar os conhecimentos constituídos como sujeito 
individual e coletivo por suas relações com os grupos sociais dos quais fazem parte. Assim, o uso situado da língua possibilita a interação, por meio da qual os sujeitos vão se constituindo e assumindo espaços sociais diversos, condicionados a variadas circunstâncias (SOUTO MAIOR, 2020). Compreendemos, desse modo, que a interação, essa inter-relação que se estabelece através da língua, "se faz presente na construção e nos efeitos de sentido do discurso, na compreensão ativa e responsiva, como numa réplica, suscitando sempre uma reação, uma resposta do interlocutor" (SILVA; ALMEIDA, 2013, p. 119). Essa resposta é repleta de afetividade, visto que as ações no mundo são geradas através dos diversos sentidos que vão sendo ratificados ou reformulados na ação e nos vários sentidos ali presentes.

No processo de interação, o discurso do falante é determinado também em função de uma possível resposta do ouvinte (o que ele/a imagina da posição do outro) que pode apresentar como contradiscurso "uma resposta, uma concordância, uma participação, uma objeção, uma execução, etc." (BAKHTIN, 2003, p. 272). Mas, nesse contexto de interação, há que se considerar as situações sociais mediatas e imediatas as quais determinam as formas enunciativas centradas na palavra, signo ideológico por excelência (BAKHTIN, 2010).
Ao compreendermos que os enunciados são determinados em função da relação dialógica entre os sujeitos, consideramos importante salientar a existência de um horizonte social definido, que estabelece a construção dos enunciados a partir do contexto social desses sujeitos (BAKHTIN, 2010). A essa relação eu e outro dá-se o nome de alteridade. A esse respeito, Bakhtin (2010, p. 117) afirma que a palavra "comporta duas faces. Ela é determinada tanto pelo fato de que procede de alguém, como pelo fato de que se dirige a alguém" no processo de interação.

$\mathrm{O}$ aspecto interacional, constituído na alteridade, pode ser fortalecido em prol de um aprendizado mais pertinente à complexidade da formação inicial em uma licenciatura; espaço que tanto prepara o/a discente para finalizar um curso com as proficiências devidas sobre o conteúdo, muitas vezes expostas nos Projetos Pedagógicos no perfil do egresso, quanto também o prepara para um saber didático pedagógico (PIMENTA, 1999; LUZ; SOUTO MAIOR, 2018) sobre esse conteúdo. Como num movimento caleidoscópico, ao mesmo tempo o saber experiencial dos cursos de formação também reforça a performance desse futuro/a docente como professor/a (SOUTO MAIOR, 2020). A seguir, trataremos das noções de Intermediação Sensível e de Ética Discursiva. 


\section{Intermediação sensível: prática ancorada na dialogicidade e na ética discursiva}

Nesse movimento interacional supracitado, a interlocução estabelecida é fundamental para a construção do saber, no âmbito do processo de ensino/ aprendizagem. Ainteração é constitutiva das relações sociais e vai construindo sentidos que geram valores, crenças, significados, pré-conceitos e noções de verdade. Cuidar desse aspecto no processo de ensino é fundamental para uma atuação mais responsável e ética do/a professor/a e uma formação mais crítica e contextualizada do/a aluno/a, principalmente quando consideramos que apenas perspectiva técnica do ensino não dá conta da sociabilidade e convivência humana.

Entendemos, assim, que o ensino pressupõe não apenas orientações conteudísticas, ou pedagógico-metodológicas, mas também ética discursivas (SOUTO MAIOR, 2020). As orientações conteudísticas, por um lado, estão relacionadas aos objetos de ensino, que tanto podem responder aos aspectos mais estruturais do signo e da normatização, quanto a aspectos estruturais discursivos. Seu foco é no "exercício" do saber, na dimensão mais técnica. Já as orientações calcadas na prática pedagógico-metodo- lógica vão destacar o como agir e o como gerenciar o ensino, a avaliação e as estratégias do ensinar. Já os aspectos da ética discursiva pressupõem as ações identitárias dos sujeitos, direcionadas à reflexão sobre quem somos nós no processo que se opera em um determinado espaço de aprendizagem vivenciado, correspondente a uma atividade de pertencimento do eu em relação ao contexto vivenciado e ao seu outro, proporcionando conexões que fortalecem a perspectiva significativa do saber sobre o conteúdo. A dimensão da ética discursiva é aquela que promove uma metadiscussão sobre como os sentidos vão estabelecendo redes de ações que reverberam em mudanças concretas na vida vivida (SOUTO MAIOR, 2020).

Nessa perspectiva, há características, por exemplo, da globalização que precisam ser questionadas, ou desnaturalizadas, independentemente do campo disciplinar no qual o/a professor/a atua, para que não haja a promoção de desigualdades e da miséria humana. Fabrício (2006, p. 46) aponta seis do que ela chama de "características mais eloquentes da globalização" e diz que a LA vem se debruçando sobre essa "trama movente" da sociedade. Dentre essas características, ela alerta para um "crescente declínio e despolitização do espaço público, decorrente do esvaziamento do sentido moral dessa arena" (2006, p. 47). Sendo assim, tanto o espaço público quanto a subjetivação dos valores desse 
espaço nos interessam, à medida que, na sala de aula, temos o desejo do coletivo compartilhado (saber da tradição, padrão de respostas, metas para a turma etc.) e o estímulo a performance autoral dos alunos e dos professores (SOUTO MAIOR, 2018).

No entanto, ao mesmo tempo em que há essa "abertura" para a subjetivação, ela é moldada pelo interesse de mercado e pela política ideológica neoliberal. Nesse sentido, Zeichner (2011, p. 63) assevera que $o$ interesse de mercado:

[...] além de responder a constante ataques para uma agenda progressista e crítica para a formação docente também tenho constantemente desafiado a lógica que separa assuntos técnicos de morais e defende que a formação inicial de professores deve concentrar-se somente em assuntos técnicos.

Nesse sentido, a língua, e consequentemente $o$ sentido, assume papel central no processo de interação social, logo nas relações dialógicas e na construção de sentidos mais éticos. Assim, sua utilização nas diversas esferas sociais requer do sujeito uma apropriação mais significativa do saber, uma vez que a língua não é apenas estrutura, mas acontece como estrutura. É importante considerar a interação estabelecida na/pela língua em contextos de ensino, uma vez que ela pode ser vista como "o lugar em que as estruturas sociais são reproduzidas, mas também como o lugar em que identidades sociais podem ser transformadas" (KLEIMAN, 1998, p. 198).
O discurso ético, nesse ínterim, é um espaço de estratégias docentes para a busca de uma autorresponsabilização do aluno sobre seu dizer, sobre o dizer sobre o outro e sobre as implicações de suas ações no mundo, como coparticipante do processo social.

Essa característica de coparticipação nas ações de sala de aula já é, de certa forma, esperada nas práticas do aluno da EaD, já que são requeridas, nessa modalidade, uma autorregulação da aprendizagem e autonomia de estudo. A coparticipação na aprendizagem de aspectos estruturais ou do saber mais tradicional ou ainda conteudista não vai desconsiderar o aspecto do sentido ou do saber novo ou do saber da práxis. Não são elementos dicotômicos, o saber técnico e o saber político, visto que o saber técnico sem autoavaliação das implicações sociais de atuação docente assume também um viés político, o da reprodução das "verdades". Mas o saber político crítico pode pôr em xeque a todo tempo a sua verdade através da constante revisão do que se está construindo para o futuro e essa ação é uma ação ética discursiva (SOUTO MAIOR, 2020). É ético por ser reflexivo, desmistificador e desnaturalizador, e discursivo por entendermos que todo processo humano é discursivo.

A observação do aspecto interacional estabelecido nos ambientes síncronos e assíncronos no contexto da $\mathrm{EaD}$, bem como a análise desse aspecto em relação 
à construção do saber e da apropriação do letramento, propicia-nos um aprofundamento importante também no campo das discussões sobre o Letramento Acadêmico. Nesse sentido, apresentamos o empreendimento de uma ação pedagógica pautada na intermediação sensível (LIMA, 2019), como ação necessária para a apropriação do letramento que, no caso deste estudo, se circunscreve no contexto acadêmico.

A intermediação sensível (LIMA, 2019) é concebida como uma prática pedagógica na qual o professor seja sensível e assuma uma postura de escuta aos diversos aspectos relacionados ao ensino e à aprendizagem de modo a atender às demandas do contexto, onde práticas de leitura e escrita são requeridas, por exemplo.

Nesse sentido, tanto as experiências extraescolares quanto as escolares - inclusive aquelas adquiridas em etapas anteriores - devem ser levadas em conta e reintegradas nas ações para a aprendizagem (LIMA, 2019). De acordo com Lima (2019), esse conceito deriva de duas categorias utilizadas em contextos nos quais a interação está presente e que requer um planejamento de ações: a escuta sensível (BARBIER, 2002) e a pedagogia culturalmente sensível (ERICKSON, 1987).

De acordo com Barbier (2002), a escuta sensível apoia-se na empatia, pois o pesquisador procura sentir o universo do outro para poder compreender comportamentos, ideias, valores e crenças, os quais, efetivamente, se relacionam com a sua atuação em dado contexto. Erickson (1987), ao discorrer sobre pedagogia culturalmente sensível, propõe que haja, por parte da escola e, por conseguinte, por parte dos professores, o empreendimento de ações que, no processo interacional, minimizem as dificuldades enfrentadas pelos alunos. Não se trata apenas de uma solução de problemas imediatos, buscando uma "eficácia" no aprendizado, mas, antes disso, trata-se da apreensão do entendimento de que há complexidade no espaço educacional e que este espaço não lida apenas com os saberes constituídos por uma herança cultural dada e concreta. Não é apenas herança dada e concreta porque o espaço de aprendizagem, como arena política, foi orquestrada em desejos de um currículo construído para determinado fim que também incorpora outros elementos do saber, desejados pela lógica mercadológica, patriarcal e neoliberal. Esses elementos, mesmo não estando explicitados, compõem o corpo de saberes apreensíveis na escola.

Dessa forma, o sensível não é sensibilidade no sentido afetivo apenas, mas significa, também, "professor atento", que parte de algo, que observa, reflete sobre o processo pedagógico no qual está inserido (LIMA, 2019), tanto sobre aspectos concretos (assunto da aula, temas inter-relacionados, conteúdo programático, textos selecionados, organização espacial etc.), 
quanto sobre aspectos subtendidos (autorizações para deslocamentos dentro da escola, pontuação sobre comportamento etc.). Assim, ele contextualiza seu fazer não a partir de um roteiro previamente "dado", mas de um conhecimento construído no diálogo em sala de aula e na observação dos elementos que a compõem.

As aulas, de um modo geral, já demandam certo encaminhamento para o favorecimento da interação, mas entendemos que as virtuais podem demandar estratégias ainda mais específicas para a integração dos alunos entre si, considerando certos gêneros de atuação. Entendemos também que uma intermediação no campo virtual que se realiza sensivelmente contribui para minimizar esse entendimento das relações à "distância", uma vez que atividades de integração que gerariam empatia podem possibilitar uma outra cultura de relação. Nesse sentido, as atividades que promovem o letramento acadêmico, por sua vez, também encontram espaço propício para seu desenvolvimento. Veremos como os espaços de fórum podem ser gêneros apropriados para essa ação docente a seguir.

\section{O gênero fórum e o letramento acadêmico}

Nossa discussão acerca de letramento acadêmico, associada ao gênero fórum, ancora-se na ideia de que o uso da língua se realiza em formas de enunciados elaborados e utilizados em determinado contexto social, cujas finalidades dependem das necessidades interacionais dos interlocutores pertencentes a determinados contextos (BAKHTIN, 2003).

Os enunciados aos quais fizemos referência-denominados gêneros discursivos - são constituídos por conteúdo temático, estilo e construção composicional (BAKHTIN, 2003) e neles são refletidas as condições específicas de produção de cada um deles. Por essa razão, é importante os sujeitos se apropriarem dos mais variados gêneros discursivos uma vez que o amplo domínio dessas formas de enunciados está associado aos mais diversos campos da atividade humana, bem como aos propósitos interacionais dos sujeitos, permitindo-lhe efetiva atuação social.

Segundo Bakhtin (2003, p. 282), "falamos através de determinados gêneros discursivos, isto é, todos os nossos enunciados possuem formas relativamente estáveis e típicas de construção do todo. Dispomos de um rico repertório de gêneros orais (e escritos)".

Da mesma forma que dispomos de um variado repertório de gêneros discursivos, também temos a nosso dispor uma variedade de letramentos os quais utilizamos nas diversas interações e contextos. No contexto universitário, por exemplo, a leitura e a produção de gêneros que nele circulam denomina-se letramento acadêmico, o qual é essencial na apropriação de conhecimentos necessários à formação 
profissional em determinado campo do saber (ZAVALA, 2010).

Assim, como uma possibilidade de utilização da linguagem de forma dialógica, a partir da leitura e produção de textos e de reflexão sobre o dizer, a modalidade de ensino a distância conta com o fórum de discussões, os quais possibilitam ações responsivas dos sujeitos, concordando, discordando, completando, respondendo, aos discursos com os quais mantêm contato (BAKHTIN, 2003).

Segundo Moore e Kearsley (2007), o gênero fórum de discussão pode ser concebido como ferramenta de comunicação nuclear em cursos a distância, pois essa ferramenta possibilita a construção de novos saberes através do entrecruzamento de vozes estabelecidas pela interatividade. Constitui-se, portanto, de um espaço interativo no qual existe um mediador e os demais seguidores, todos visualizando os textos postados e com possibilidade de intervir discursivamente (BRUNO; HESSEL, 2007). Apesar desse aspecto inerente ao fórum de discussão, alguns pesquisadores têm chamado a atenção acerca da ausência de interação através dessa ferramenta, pois muitas vezes a participação de sujeitos nela envolvidos não assegura uma efetiva interação, pois há poucos indícios de dialogicidade, o que pode comprometer a troca de conhecimentos e que pode estar relacionada à ausência de um processo de intermediação sensível.
Essa discussão pressupõe mais explicitamente pelo menos duas atuações: a de quem aprende e a de quem ensina. Essa atuação discente defasada pode estar atrelada à crença de que há o aprendizado solitário nessa modalidade de ensino. Muitas vezes o aluno vai naquele espaço "cumprir uma atividade do roteiro recebido", mas sem se dar conta de que há naquele espaço uma comunidade, ou seja, um coletivo. Não se trata, pois, de um mero repositório. Batista (2013), por exemplo, alerta-nos que, no contexto do ensino a distância, grande parte dos professores utiliza os fóruns como repositório de atividades, não privilegiando suas potencialidades como um espaço de dialogicidade inerente à construção do conhecimento.

A atuação docente não sensível, por sua vez, pode estar atrelada ao fato de só se privilegiar o aspecto mais técnico-estrutural do aprendizado. Ao docente caberia "conferir" a atividade, sem levar em consideração os aspectos ético-discursivos, conforme apresentamos mais acima.

$\mathrm{Na} \mathrm{EaD}$, contexto sobre o qual nos debruçamos neste estudo, a intermediação sensível pode ser exercida em várias modalidades de atuação nas diversas atividades que $\mathrm{o}$ ambiente proporciona. $\mathrm{O}$ gênero fórum de discussão é uma dessas instâncias que, talvez, por excelência, possa ser um espaço onde o exercício do diálogo sensível (com réplicas, orientações, confirmações, contraposições etc.) possa 
estar presente. Abaixo, apresentaremos reflexões de como isso pode ou não ocorrer.

\section{A interpretação dos acontecimentos}

Como dito na introdução, assumimos a abordagem qualitativa de pesquisa que, dentre outras características, não visa ao estabelecimento de relação causal nas práticas analisadas. A perspectiva adotada é interpretativista análise do discurso LA.

A partir da análise geral das informações da pesquisa, foram registrados dois tipos de interação: a presencial e a on-line. Selecionamos como corpus para análise: dois momentos presenciais, com a participação do professor e de 30 alunos/as; três trechos de interação on-line: de uma aluna e do professor do curso.

Tal seleção se justifica pelos critérios de considerarmos todas as possibilidades de interação no ambiente EAD (momentos presenciais e on-line) e a participação dos/as colaboradores/as. Para a organização da análise, dividimo-la em três subtópicos, um referente aos dois momentos interacionais na aula presencial, quando da exposição do assunto da disciplina; um referente às duas participações de alunas nos fóruns e um à participação do próprio professor.

Interação na aula presencial: intermediação sensível e o discurso do outro - para iniciarmos a análise, destacamos alguns aspectos relacionados ao processo de interação entre professor/a - aluno/a e necessários à promoção do letramento acadêmico. Para aprofundarmos na discussão, recorremos às noções de intermediação sensível (LIMA, 2019) e de ética discursiva (SOUTO MAIOR, 2018).

A aula presencial transcorreu com a leitura, pelo professor, de alguns textos teóricos relacionados à temática abordada, seguida da apresentação da organização do Ambiente Virtual de Aprendizagem (AVA) no decorrer da disciplina. Já percebemos, nessa estrutura de apresentação de aula, os dois núcleos de saberes selecionados: o do saber sobre o tema (conteúdo) e o do saber sobre a prática digital (técnica).

Nesses episódios da aula, houve diálogos pontuais sobre questões abordadas nos textos, mas não foi possível observar concretamente se os/as alunos/as estariam se apropriando de conceitos que poderiam integrar um construto teórico condizente com os saberes necessários de um profissional de Letras, pois, além de as propostas discursivas do professor serem intercaladas por momentos de silêncio - podendo indicar, dessa forma, certa apatia, desestímulo, desconhecimento do tema por parte dos/as discentes -, o professor parecia não promover espaços interacionais a partir desse silêncio constatado, ou da não participação dos/as discentes, quando tais conceitos relacionados à língua e à linguagem eram apresentados. A 
partir dessa reação, podemos afirmar que o ativismo silente dos/as alunos/as participantes do estudo, indicam, do ponto de vista da ética-discursiva, que eles/as não estavam se apropriando adequadamente do conteúdo exposto. O saber poderia não ser, nesse ínterim, um saber para a atuação mais reflexivo-crítica. Vejamos a situação analisada no Quadro 1:

Quadro 1 - Apresentação da proposta de trabalho

Bom gente é:: como eu percebi todos têm uma tendência ao curso, ou...ou os que não tinham o pessoal que escolheu por...pela opção tá gostando, eu já digo que a gente nessa disciplina ((pigarreou)) que é uma disciplina bastante é:: teórica, nós vamos estudar teoria da linguagem, né?! $E$ vocês vão entender mais ou menos o que é uma teoria, sobre o fenômeno linguagem é:: muitas questões que serão postas aqui, talvez vocês nunca pararam efetivamente pra pensar por que a nós enquanto falantes ou usuários da língua, usamos a língua e ponto, não...não refletimos sobre a língua efetivamente, né? Mas nessa disciplina sim, é parar para observar o fenômeno linguagem, né? É uma disciplina que vai requerer algumas leituras, sim! É por isso eu perguntei, né? E gostei de saber que a grande maioria daqui gosta de ler/ ou ninguém daqui disse que não gosta de ler, no caso isso já foi bom, ninguém disse: professor eu não gosto de ler, né? Ninguém disse isso. Então é: vocês vão precisar realmente que de um tempo, por ser uma disciplina muito teórica, talvez muitas questões fiquem nebulosas ainda, né?! Mas enfim! Vocês vão // é como eu disse a disciplina/ vocês vão ter contato com linguística, durante todo o curso, né?! $E$ a gente vai discutindo, nos fóruns, por exemplo, essas questões sobre linguagem...

Fonte: dados da pesquisa de Lima.

Em um dos momentos da aula, o professor orientou que seria necessário fazer pesquisas para a compreensão dos conceitos (essas concepções que aparecem nesses materiais que vocês estão lendo... quer dizer, pesquisando... vão fundamentar o fórum - trecho quadro 2), mas de uma maneira bem generalizante, sem informações didaticamente sistematizadas sobre o ato de pesquisar. Essa seria uma das práticas docentes que muito se adequaria aos encaminhamentos de uma intermediação sensível à formação de um/a professor/a numa perspectiva de Letramento acadêmico, visto que seria uma orientação para a postura de pesquisa no estudo. Apesar de que o professor, de certa forma, indica espaços para o desenvolvimento das discussões nos fóruns, como vemos no Quadro 2:

Quadro 2 - Considerações do professor sobre atuação no fórum

A primeira semana tem um fórum... Oh, já tem um
fórum aí, sobre as concepções de língua e lingua-
gem e uma atividade, ok?... Mas, enfim, amanhã
eu explico com mais detalhe cada ... cada uma
das atividades que serão// que a gente vai fazer
durante a disciplina.
O fórum/ tô sem internet/ O fórum ele é disponi-
bilizado durante to::da a disciplina...ele vai ficar
aberto...não é uma avaliação quantitativa...não
tem ponto para a participação no fórum, né? Mas
tem aquela chamada avaliação qualitativa de par-
ticipação que pode também..., os tutores já estão
cientes disso, podem influenciar caso vocês preci-
sem de nota, por exemplo... então recomenda-se
que vocês participem da:: do fórum
E o fórum é sobre as concepções de língua
e linguagem e aí vocês vão é:: apresentar...
discutir junto comigo e com os tutores essas
concepções que aparecem nesses materiais
que vocês estão lendo... quer dizer, pesquisan-
do... vão fundamentar o fórum...conectou..((en-
quanto falava, o professor buscava uma conexão
com a internet))

Fonte: dados da pesquisa de Lima. 
O que destacamos ainda em referência ao quadro 1 é que o docente não forneceu orientações acerca de como os/as alunos poderiam se apropriar do discurso do outro, nem nas pesquisas e nem nos fóruns, sobre a língua e linguagem apresentadas como conceitos basilares na formação de professores de línguas, o que corrobora para a prática institucional de mistério no contexto do letramento acadêmico (LILLIS, 1999). Orientar sobre o gênero fórum teria sido fundamental para a apropriação do gênero e discutir sobre a citação da palavra do outro seria substancial para uma reflexão acerca das noções de plágio, das características próprias do gênero acadêmico resumo e resenha e da funcionalidade do argumento de autoridade, itens que compõem movimentos da ética discursiva na esfera universitária.

O professor rearticula as orientações para o espaço do fórum já que elas pareciam não acontecer presencialmente. No entanto, teria sido na aula presencial o momento propício para introduzir práticas que fossem importantes ao entendimento do processo de aprendizagem no campo da EaD e na dimensão do sentido da aprendizagem dialógica. O professor naquele espaço precisava, portanto, numa ação de intermediação sensível, estabelecer os papéis dos participantes, chamando-os a uma participação mais efetiva, e elencar elementos dessa participação, a saber: 1) necessidade de socialização do aprendizado; 2) postura de pesquisador/a reflexivo/a; 3 ) apropriação da linguagem adequada ao gênero; 4) ação ética na linguagem; 5) prática dialógica nos ambientes de aprendizado (no caso, o fórum).

A observação desse cenário, o modo como essa prática de letramento se configurou, pareceu-nos corresponder a outra problemática apresentada por Lillis (1999), no que se refere à interação. Ao fazer referência a Bakhtin, a autora argumenta que uma das razões que dificulta a compreensão é a falta de locutores reais. Podemos entender que essa falta de locutores reais, mencionada pela autora, está relacionada ao distanciamento entre o que o professor apresenta e a compreensão dos alunos, diante do que lhes são apresentados. A maneira como o saber é trabalhado pode ser fundamental para uma apreensão mais significativa. Isso por considerarmos que, em função de a maioria desses/as alunos/as serem recém-ingressos/as em um curso superior, as convenções inerentes a esse domínio, as especificidades dos discursos e dos gêneros acadêmicos "muitas vezes se constituem num mistério" para eles/ elas (LILLIS, 1999, p. 129). A seguir, o outro campo de análise, agora on-line, será discutido.

Interação nos fóruns: intermediação necessária - após as explanações do conteúdo nos momentos presenciais, a primeira oportunidade de escrita dos/ 
as alunos/as ocorreu quando o professor apresentou o fórum com o tópico de discussão, a partir da seguinte proposta:
"Diferenças entre Língua e Linguagem

e Concepções de Língua/Linguagem”.

Figura 1 - Proposta do professor para participação no fórum

Fórum - Diferenças entre Língua e Linguagem e Concepções de Língua/Linguagem quarta, 4 Set 2013, 15:35

Caros alunos,

Antes de começarmos os estudos sistemáticos sobre Teoria Linguística, faz-se necessária uma incursão preliminar sobre questões básicas acerca da linguagem. Para tanto, pesquisem (na internet, em livros, revistas etc.) sobre as diferenças entre língua e linguagem e sobre as concepções de língua/linguagem existentes, expondo seus comentários neste fórum. Lembrem-se de que um dos Dontos de avaliacão do curso é a efetiva Darticidacão nos foruns de discussão.

Fonte: dados da pesquisa de Lima.

O fórum de discussão que adotamos como objeto desta análise, conforme visualizamos na Figura 1, foi o único proposto pelo professor supracitado, e também a primeira oportunidade de escrita dos/as alunos/as na disciplina que já havia iniciado há duas semanas. Esse fórum mantinha as mesmas características dos demais fóruns em EaD: foi utilizado de modo assíncrono e deveria ser gerenciado pelo professor e tutora; aquele primeiro iniciou a interação apresentando um tópico de discussão, solicitando dos/as alunos/as uma participação concreta. Assim, cada sujeito postava "como textos-resposta" para todos/as os/as participantes, ou de forma mais específica, focalizando seu discurso no tópico de discussão.

O que percebemos também é que há uma grande diferença entre a quantidade de postagens dos alunos e as do professor e tutora, o que vai de encontro à natureza dialógica do fórum em contextos de ensino e aprendizagem, que é a promoção de discussões sobre determinados conteúdos a fim de que os sujeitos envolvidos nesse contexto se apropriem dos conhecimentos relacionados à sua formação (PRIMO, 2006). Analisamos que se houve reorientação de que no fórum seria o espaço para as discussões após as primeiras apropriações dos conceitos, lamentavelmente ela não foi efetivada.

A forma como é estabelecida a interação entre professor, tutora e alunos e deles entre si compromete a apropriação do letramento acadêmico em função da impossibilidade do acompanhamento do seu processo de construção de conhecimento (PRIMO, 2006), visto que no fórum não houve debates, o que acarretou na não reflexão sobre a condição letrada do/a aluno/a em razão na não intermediação sensível do professor e da tutora.

É importante destacar que a forma como o discurso é construído no tópico de 
discussão do fórum tem significativo papel para o gênero porque uma discussão dessa natureza deveria envolver perguntas, orientações, informações, repostas, análises e sínteses, como sugere Santos (2001) dos participantes. Também é importante destacar que uma discussão sobre concepções de língua e linguagem é basilar na formação dos futuros professores de línguas porque subsidia suas práticas a partir de suas escolhas teóricas, pois, de acordo com Santos (2007, p.150), "qualquer prática pedagógica não prescinde de concepções subjacentes que direcionam, determinam todo o trabalho desenvolvido".

Vemos que, no tópico de discussão supracitado (Figura 1 - Proposta do professor para participação no fórum), $o$ professor propôs a exposição de comentários acerca de questões básicas que envolvem a linguagem, que, como pontuado anteriormente, constitui-se num dos temas importantes para a formação de um/a professor/a de línguas. Ele sugere pesquisas em diversos contextos, mas não identificamos, no seu dizer, que a postagem deveria ser apenas transcrição das informações encontradas nas fontes de pesquisa consultadas; sua proposta foi de haver discussão entre ele, tutora e alunos/as sobre tais questões. Ao anunciar o tópico de discussão, o professor solicitou que os/as alunos/as discutissem com ele "e com os tutores" as concepções encontradas em suas leituras, retifican- do o termo como pesquisa no momento da aula presencial, conforme vemos no Quadro 4:

Quadro 4 - Transcrição da proposta do professor "vocês vão é:: apresentar... discutir junto comigo e com os tutores essas concepções que aparecem nesses materiais que vocês estão lendo... quer dizer, pesquisando...".

Fonte: dados da pesquisa de Lima.

Nesses dizeres do professor podemos perceber seu desejo de dialogar acerca do conteúdo abordado, cujo respaldo dar-se-ia a partir das pesquisas efetuadas pelos/as alunos/as. Nesse contexto, observamos, no professor, a crença de que os alunos concebiam pesquisa como um trabalho de busca, no qual a investigação pressupunha autointerrogação e autoanálise, como indica Morin (2000).

No entanto, a partir do que observamos em algumas postagens no fórum, $o$ conceito de pesquisa que os/as discentes demonstraram ter configurou-se apenas como uma reprodução dos conteúdos lidos ou pesquisados, que responde a dimensão técnico-estrutural, não a ético-discursiva.

Essa problemática passou despercebida, pois não identificamos intermediação que visasse ao letramento acadêmico daqueles discentes, nem por parte do professor nem da tutora, acerca do conceito de pesquisa esperado, como já explicitamos acima. 
Faltou, portanto, uma postura de intermediação sensível, por parte do professor da turma, na busca da construção dos saberes necessários para a construção da identidade docente do/a formando/a em Letras. Não expor, objetivamente, como a prática de pesquisa era definida para a efetivação do trabalho, reforçou a visão de prática de pesquisa como cópia. Mesmo que, inicialmente e por um lado, ele não tivesse se dado conta dessa crença, o processo de acompanhamento de fórum seria um momento importante para a reformulação dessa prática de letramento. Uma prática de tamanha importância como é a de pesquisa poderia ter sido amplamente discutida, principalmente por se tratar de uma turma iniciante no universo acadêmico. Podemos considerar, por outro lado, que o professor já esperasse esse saber como consolidado nas formações, mas isso só reforça a necessidade de nos transportarmos ao campo das desnaturalizações docentes.

Uma das alunas (por uma questão de preservação da identidade, ela é denominada de Lara nesta pesquisa), por exemplo, em resposta à solicitação do professor, apresentou uma reprodução retirada do texto fonte de sua "pesquisa", conforme observamos na Figura 2:

Figura 2 - Primeira postagem de Lara

\begin{abstract}
A linguagem é a capacidade que os seres humanos têm para produzir, desenvolver e compreender a língua e outras manifestações, como a pintura, a música e a dança. Já a língua é um conjunto organizado de elementos (sons e gestos) que possibilitam a comunicação. Ela surge em sociedade, e todos os grupos humanos desenvolvem sistemas com esse fim. As línguas podem se manifestar de forma oral ou gestual, como a Língua Brasileira de Sinais (Libras).

fontes de pesquisa:

revistaescola.abril.com.br
\end{abstract}

Fonte: dados da pesquisa de Lima.

Ao analisarmos essa postagem de Lara, percebemos que sua resposta apresenta inadequações em alguns aspectos, como em relação à ausência de elementos discursivos que poderiam evidenciar uma postura ético discursiva em relação à reflexão do outro; tampouco suscita interações com as postagens anteriores, ação esperada na performance no gênero. Esses indícios apontam também para uma lacuna no Letramento Acadêmico referente à apropriação da prática no gênero fórum.

Embora trate do tema em discussão, a aluna não alcança os objetivos propostos pelo professor, que seria discutir sobre as concepções de língua e linguagem. Discussão pressupõe uma "reflexão sobre" e o que a aluna efetiva é uma ação de "copiar e colar", além de não, como dissemos acima, referir-se aos discursos já inscritos no ambiente. Observamos que 
a aluna também compreende pesquisa como "reprodução de fragmentos do texto fonte", apesar de, nessa postagem, ela também evidenciar uma produção textual configurada relativamente nos parâmetros acadêmicos, já que há citação da fonte de pesquisa, mas isso não se configura ainda numa dimensão ético discursiva de uma prática mais crítica sobre a escrita. Ela não demonstra adequado domínio do gênero acadêmico e, consequentemente, das práticas de Letramento Acadêmico.

Sabemos que, na $\mathrm{EaD}$, o fórum é um lugar privilegiado no processo de ensino e aprendizagem e, nesse contexto, é de grande relevância o papel do/a professor/a e do/a tutor/a, pois, a partir de suas orientações, os alunos podem refletir sobre seus processos de escrita e aprimorar sua condição letrada. É também do nosso conhecimento que tanto o professor quanto o tutor atuam em outras instâncias, o que requer desses sujeitos disponibilidade para atender às demandas inerentes ao processo de ensino nesses diversos espaços. No contexto a distância, tal demanda se acentua, pois, nessa modalidade, segundo Coelho (2010, p. 50), o

[...] papel do professor sofre imensa modificação; deixa de ser predominantemente o centro do processo e passa a acompanhá-lo, pois exige-se do professor competência de tutoria, autoria, gestão, avaliação [...].
Nessa nova configuração do/a professor/a para atuar no contexto do ensino a distância, sua intermediação sensível nos fóruns é imprescindível, uma vez que eles se constituem como uma representação do espaço educativo mais dialogal e interativo, e também de práticas de letramento, pelo fato de neles poderem ser registrados as produções dos sujeitos envolvidos no processo de formação como réplicas principalmente. Além disso, possibilita, a qualquer tempo, seu acesso a elementos como conteúdos a serem discutidos, exposição de aprendizagens e dificuldades dos alunos, o que o torna, também, um relevante instrumento de avaliação (BARRETO, 2007). Assim, ao analisarmos a atuação do professor no fórum, compreendemos que as questões discutidas nessa ferramenta de comunicação precisariam estar explicitadas e compreendidas, a fim de que a interação se concretizasse de modo significativo para a aprendizagem dos alunos, numa dimensão técnico-estrutural e ético-discursiva.

\section{Conclusão}

A partir dessas reflexões, constatamos a importância da intermediação sensível (LIMA, 2019) através dos fóruns no processo de escrita dos/as alunos/as, pois é possível ao professor discutir com eles/as tanto aspectos da produção textual como a utilização de 
operadores discursivos inerentes ao gênero que estão produzindo e sentidos ali implementados por essa utilização, bem como formas de apresentação de conceitos, que os instiga à reflexão sobre os diversos aspectos de suas produções. Entretanto, não observamos esse encaminhamento por parte do professor, nem da tutora, conforme apresentado anteriormente, quando Lara produziu um texto apresentando equívocos conceituais. Essa postura adotada pelo professor no processo de ensino e aprendizagem implica uma formação deficiente, podendo constituir-se para a permanência das “dimensões escondidas que emergem nas avaliações da escrita acadêmica, e que muitas vezes permanecem implícitas" (STREET, 2010, p. 542).

A partir da situação retratada, verificamos que, em $\mathrm{EaD}$, a utilização do fórum enquanto gênero no qual se efetivam práticas de letramento está condicionada à intermediação sensível do professor ou do tutor, pois nesse contexto de ensino, no qual os espaços discursivos são reconfigurados em função das TDIC, há a possibilidade de o/a aluno/a:

[...] mergulhar em um mundo virtual cuja comunicação se dá essencialmente pela leitura e interpretação de materiais didáticos textuais e hipertextuais, pela leitura da escrita do pensamento do outro, pela expressão do próprio pensamento por meio da escrita (ALMEIDA, 2003, p. 338).

Toda essa ação por parte do aluno pode ser compreendida como um ato de responsividade, onde ele, na condição de sujeito aprendiz não reproduz passivamente as informações apresentadas pelo professor/tutor. Ou seja, não se

[...] espera uma compreensão passiva, por assim dizer, que apenas duble o seu pensamento em voz alheia, mas uma resposta, uma concordância, uma participação, uma objeção, uma execução etc. (BAKHTIN, 2003, p. 272).

Embasados nessas reflexões de Bakhtin (2003) e analisando esse contexto de formação, acreditamos que foi na perspectiva da responsividade que o professor propôs o fórum, solicitando aos/às alunos/as que expusessem seus comentários.

No momento presencial, inclusive, ele demarcou qual deveria ser o posicionamento dos/as alunos/as quando ratificou a diferença entre "ler" e "pesquisar". No momento a distância, através do tópico de discussão, foi reiterada a ideia da pesquisa, além de asseverar a importância da participação no fórum como um dos requisitos de avaliação, quando ele solicitou aos alunos que pesquisassem "sobre as diferenças entre língua e linguagem e sobre as concepções de língua/linguagem [...], expondo seus comentários" e enfatizou que um dos pontos de avaliação seria a "efetiva participação nos fóruns de discussão". Entretanto, nesse fórum, foram apresentadas 83 postagens, das quais 17 dos sujeitos de pesquisa, uma da tutora e uma do professor, excetuan- 
do-se a da abertura da discussão, que é apenas postada pelo professor.

\section{The sensitive intermediation and discursive ethics in academic literacy process a distance learning context}

\section{Abstract}

This article aims to analyze the learning process of teachers in initial formation within the discussions on academic literacy. Using theoretical-methodological assumptions of Applied Linguistics, we adopted the interpretive perspective of research to analyze face-to-face moments and the distance of interactions between teacher and students in the discussion forum and in face-to-face classes of a curricular component offered in the first semester of the Language / Portuguese course of a Federal Institute. After the analysis, we concluded that the observed events are related to driving in class (presential and non-presential moments) not consistent with an effective and meaningful academic literacy process. For the development of a more effective practice, we concluded that there should be a pedagogical practice of sensitive intermediation, associated with the production in a perspective of discursive ethics, so that future teachers could act in response to the demand for more autonomous and critical training

Keywords: Academic literacy. Sensitive intermediation. Discursive ethics. Teacher formation.

\section{Referências}

ALMEIDA, M. E. B. de. Educação a distância na internet: abordagens dos ambientes digitais de aprendizagem. Educação e Pesquisa, São Paulo, v. 29, n. 2, p. 327-340, jul./dez. 2003.

LIMA, Antônio Carlos dos Santos de. $D a$ necessidade de uma intermediação sensível: reflexões sobre letramento acadêmico em um contexto de educação a distância do IFAL. Tese (Doutorado em Linguística) - Faculdade de Letras, Universidade Federal de Alagoas, Maceió, 2019.

SOUTO MAIOR, Rita de Cássia. Os saberes docentes e a construção de ethos no PIBID/ Letras: a construção de uma ética discursiva. In: FIGUEIREDO, F. J. Q. de; SIMÕES, D. (org.). Contribuição da Linguística Aplicada para a Educação Básica. Campinas: Pontes Editores, 2018.

SOUTO MAIOR, Rita de Cássia. A constituição de uma ética discursiva na prática docente e os papeis afetivo-identitários na produção do saber. 2020. Mimeo.

BAKHTIN, M. Estética da criação verbal. 4. ed. São Paulo: Martins Fontes, 2003.

BAKHTIN, M. Problema da Poética de Dostoiévski. 3. ed. Rio de Janeiro: Forense Universitária, 2005.

BAKHTIN, M. Marxismo e filosofia da linguagem. 12. ed. São Paulo: Hucitec, 2010.

BARBIER, R. Escuta sensível na formação de profissionais da saúde. In: L'ecoute sensible dans la formation des professionnels de la santé. Conference à l'Ecole Supérieure de Sciences de la Santé. 2002. Disponível em: http://www.saude.df.gov.br. Acesso em: 30 jun. 2020.

BARRETO, L. A. N. O fórum como instrumento de avaliação da aprendizagem em educação a distância. E-Revista Facitec, v. 1, n. 2, art. 6, dez. 2007. 
BATISTA, E. M. Interações em um curso de Pedagogia a distância: características, limites e possibilidades. Tese (Doutorado em Educação) - Centro de Ciências Humanas e Sociais, UFMS, Campo Grande, 2013.

BRUNO, A. R.; HESSEL, A. M. D. G. Os fóruns de discussão como espaços de aprendizagem em ambientes on-line: formando comunidades de gestores. 2007. Disponível em: http://www.abed.org.br/congresso2007/ tc/420200712027PM.pdf. Acesso em: 30 jun. 2020.

CASTELLS, Manuel. A sociedade em Rede: a era da Informação: Economia, Sociedade e Cultura vol. 1. São Paulo: Paz e Terra, 2009.

COELHO, D. H. de A. O papel do professor na EaD. Interação - Revista de Ensino, Pesquisa e Extensão, v. 12, n. 12, 2010.

ERICKSON, F. Transformation and school success: the politics and culture of educational achievement. Anthropology \& Education Quarterly, v. 18, n. 4, 1987.

FABRÍCIO, B. F. Linguística Aplicada como espaço de desaprendizagem: redescrições em curso. In: MOITA LOPES, L. P. et al. (org.). Por uma Linguística Aplicada Indisciplinar. São Paulo: Parábola Editorial, 2006.

FREITAS, Maria Teresa de Assunpção. A perspectiva sócio-histórica: uma visão humana da construção do conhecimento. In: FREITAS, M. T. et al. Ciências Humanas e Pesquisa: Leitura de Mikhail Bakhtin. São Paulo: Cortez, 2003.

KLEIMAN, A. Ação e mudança na sala de aula: uma pesquisa sobre letramento e interação. In: ROJO, R. (org.). Alfabetização e letramento: perspectivas linguísticas. Campinas: Mercado de Letras, 1998.

LILLIS, T. Whose "common sense"? Essayist literacy and the institutional practice of mystery. In: JONES, C.; TURNER, J.; STREET, B. (org.). Students writing in the university: cultural and epistemological issues. Amsterdam: John Benjamins, 1999.
LÜDKE, Menga; ANDRÉ, Marli E. D. A. A pesquisa em educação: abordagens qualitativas. São Paulo: EPU, 1986.

LUZ, L. S. de F.; SOUTO MAIOR, R. de C. Reflexões sobre a construções identitárias de docentes de educação a distância partir da análise linguístico discursiva de interações no gênero consígnia. $D L C V$, v. 14, n. 2, 2018.

MOITA LOPES, L. P. da. Oficina de linguística aplicada: a natureza social e educacional dos processos de ensino/aprendizagem de línguas. Campinas: Mercado de Letras, 1996.

MOITA LOPES, L. P. da. Por uma linguística aplicada indisciplinar. São Paulo: Parábola Editorial, 2006.

MORIN, J. M. Ensino e Aprendizagem inovadores com Tecnologias Informática na Educação: Teoria \& Prática, v. 3, n. 1, 2000.

MOORE, M. G.; KEARSLEY, G. Educação a Distância: uma visão integradora. São Paulo: Thomson Learning, 2007.

OLIVEIRA, M. M. de. Como fazer pesquisa qualitativa. 2. ed. Petrópolis: Vozes, 2008.

PIMENTA, Selma Garrido. Formação de professores: identidade e saberes da docência. In: PIMENTA, Selma Garrido (org.). Saberes pedagógicos e atividade docente. São Paulo: Cortez Editora, 1999. p. 15-34.

PRIMO, A. Avaliação em processos de educação problematizadora online. In: SILVA, M.; SANTOS, E. (org.). Avaliação da aprendizagem em educação online. São Paulo: Loyola, 2006.

SANTOS, M. M. C. Texto didático: propriedades textuais e pressupostos epistemológicos. Caxias do Sul: Educs, 2001.

SANTOS, L. F. Produção de textos na universidade: em busca de atitudes ativas e táticas. Tese (Doutorado em Linguística) - Faculdade de Letras, UFAL, Maceió, 2007.

SILVA, R. O.; ALMEIDA, M. F. Análise da interação verbal na teoria bakhtiniana. 
Macabéa, Revista Eletrônica do Netlli, v. 2, n. 1, 2013.

STREET, B. Dimensões "Escondidas" na Escrita de Artigos Acadêmicos. Perspectiva, Florianópolis, v. 28, n. 2, p. 541-567, jul./ dez. 2010.

ZAVALA, V. Quem está dizendo isso? Letramento acadêmico, identidade e poder na educação superior. In: VÓVIO, C.; SITO, L.; DE GRANDE, P. (org.). Letramentos: rupturas, deslocamentos e repercussões em Linguística Aplicada. Campinas: Mercado de Letras, 2010.

ZEICHNER, Kenneth M. A pesquisa-ação e a formação docente voltada para a justiça social: um estudo de caso dos Estados Unidos. In: DINIZ-PEREIRA, Júlio E.; ZEICHNER, Kenneth M. (org.). A pesquisa e a formação no trabalho docente. Belo Horizonte: Autêntica, 2011. 